\title{
Application of profilograph for evaluation of mechanical tillage of slope lands
}

\author{
Mikhail Vasiliev ${ }^{1}$, Sergey Vasiliev ${ }^{1,2, *}$, and Alexey Vasiliev ${ }^{2}$ \\ ${ }^{1}$ Department of Applied Mechanics and Graphics, Chuvash State University named after I.N. \\ Ulyanov, 428015, Cheboksary, Russia \\ ${ }^{2}$ State Budget Educational Institution, Nizhny Novgorod State University of Engineering and \\ Economics, 606340, Knyaginino, Russia
}

\begin{abstract}
In this paper, we analyze a wide range of measurements of the day surface profile of tilled soil in order to substantiate the moving average method for evaluating morphological parameters and studying the influence of the base profile length on the accuracy of the obtained values. The surface roughness of the elementary plot was $4 \mathrm{~mm}$, the surface ridgeness formed by technological furrows was $16 \mathrm{~mm}$, and the slope of the plot was 0.198. The accuracy of the obtained values of roughness and ridgeness of the tilled soil surface depends significantly on the profile length determined by the number of measurements performed. We obtained 5273 data points per one turn of the device on a $6.3 \mathrm{~m}$ profile length ( 1 measurements are made per $1 \mathrm{~mm}$ ) for the elementary plot. The surface roughness varied from $3,1 \mathrm{~mm}$ to $4,3 \mathrm{~mm}$, and the ridgeness $-12 \ldots$ $21 \mathrm{~mm}$ when the number of measurements is from 2000 to 5273 . When the measured profile length is about $1.3 \mathrm{~m}$ or less (not more 2000 points), the parameters of the tilled soil cover are not considered important. However, they are more critical for ploughed soil than for harrowed soil. On flatter surfaces, the base profile length of $2.5 \mathrm{~m}$ may be sufficient to adequately calculate the parameters of the day soil surface.
\end{abstract}

\section{Introduction}

The soil surface roughness of the agricultural landscape plays an important role in a number of agrochemical as well as physical and mechanical processes occurring at the "soilatmosphere" system interface [1, 2]. Infiltration, watercourse formation and soil erosion are among the phenomena that are typical for the agricultural landscape of slope lands. Rough soil surface which has a lot of irregularities and hollows takes less time for moisture infiltration. Moreover, rough soil surfaces reduce the flow rate and the intensity of erosion processes compared to flatter soil surfaces. In general, rough tilled surfaces create favorable conditions for the moisture accumulation and the preservation of soil fertility in the agricultural landscape on the slopes.

The most commonly used indicator of soil roughness is the so-called accidental roughness, which is the standard deviation of surface heights [2, 3]. Soil surface roughness

\footnotetext{
*Corresponding author: vsa_21@mail.ru
} 
refers to vertical changes present in the micro - and macro-relief of the soil surface, as well as to their stochastic distribution. It is a characteristic vertical scale of the length of microrelief variation from individual soil grains to soil aggregates ranging from 1 to $10 \mathrm{~mm}$. Soil surface waviness (ridgeness) has certain curvature or its macroscopic topographic features [4]. Ridgeness is a range of irregularities where the distances between adjacent elevations or hollows exceed the base length for the surface roughness. Roughness is quantified by a random value, which is essentially the standard deviation of surface elevation data from the average height value after the correction using the best fit plane and elimination of tillage effects in some height values, what is noted document [5] and GOST 25142-82 " surface Roughness. Terms and definitions" GOST ISO 4287-2014.

Recently, short-range photogrammetric methods [6, 7] and ground-based laser scanning devices $[8,9,10]$ have been used to obtain high resolution digital surface models. These methods can potentially provide information about the height of points over large areas. However, photogrammetry is performed at close distance for areas up to $1 \mathrm{~m}^{2}$. On the other hand, laser scanners could scan areas up to $10 \ldots 100 \mathrm{~m}^{2}$, but these devices gave poor results when measuring larger areas of soil surface [11].

Another important characteristic of agricultural soils on slope lands, which has not been studied in detail yet, is the relationship between the direction of the slope and the direction of arable technological furrows or ridges. The angle between the furrows of the tilled soil and the slope direction significantly affects the precipitation flow $[12,13]$. However, as far as the authors know, the influence of the tillage direction relative to the slope on the soil parameters has not been quantified yet.

The purpose of the research is to substantiate the moving average method for assessing the morphological parameters of the day surface of tilled soil and to study the influence of the profile length of the surface height on the accuracy of the obtained values.

\section{Research methods}

The research was conducted in the agricultural catchment area of Orininskoe rural settlement located in the Morgaushsky district of the Chuvash Republic (figure 1). This area includes Padakkasy GTS with a water source and makes a part of the drainage-area of the Morgaushka river. The studied catchment area covers about 300 ha. About $8 \%$ of the area is fairly complex slopes and its height varies from 152 to $185 \mathrm{~m}$. The climate is moderately continental with long cold winters and warm summers. The average annual precipitation is about $500 \mathrm{~mm}$. The predominant class of soils is sod - podzolic with varying degrees of podzolization [14, 15]. The catchment area is almost completely cultivated, and the chain of ravines, borders of water sources and streams are the only areas that are covered with natural vegetation. The main crops are perennial grasses (bromegrass, alfalfa) and winter cereals (wheat and barley).

Three agricultural fields were selected on the catchment area, ranging from 25 to 53 ha (see figure 1). The studied areas were cultivated in various ways: plot 1-plowing with harrowing (PLN-4-35+BZTC-1); plot 2 - soil disking (disc harrow BDM-3x4P); plot 3 under-winter plowing (PLN-4-35), then the work was analyzed. [2, 16].

The profiles of elementary plots were measured using the originally developed groundbased circular laser profile meter $[8,9]$. An elementary plot is an area that can be characterized either by studying the day soil surface or taking combined soil sample, according to GOST 28168-89 "Soil. Sample taking».

The device has a laser sensor that measures the distance between the sensor itself and the soil surface (figure 2). The profilograph consists of a steel base with an axis to which a cross bar is attached. The laser sensor is placed on the carriage located on one side of the bar and can be moved along the bar manually when a given circle radius is set. This sensor 
has a vertical accuracy of $\pm 0.5 \mathrm{~mm}$ and a measurement range of up to $1 \mathrm{~m}$, which makes it suitable for measuring and monitoring slope elementary areas of tilled soils and assessing manifestation of erosion processes on them that is measuring erosion hollows and micro waterways. The profilograph is programmed to collect data on the height of points located along the scanning circle every 0.02 seconds and to store them. The total base length of the surface profile can reach 6.5 meters when the working radius of the sensor is $1 \mathrm{~m}$ or more. The base line used to determine irregularities characterizes the surface roughness, according to GOST 25142-82 "Surface roughness. Terms and definitions". The device contains a signal processing unit that receives signals from a laser sensor to measure the distance and an angle encoder to determine the position of the bar with the sensor on the axis. The device is powered by a laptop which stores and processes information about the received profiles. The process of measuring data is fairly simple and fast. As soon as the first data on the surface profile are displayed on the computer in polar coordinates the operator turns the bar counterclockwise or clockwise around the axis [9]. Then, using regression analysis, each of the height profiles is adjusted to get an array of true height values for the measured slope. Further, the profiles are processed by a specially developed program in the Excel system to calculate the parameters of slope, ridgeness and surface roughness.

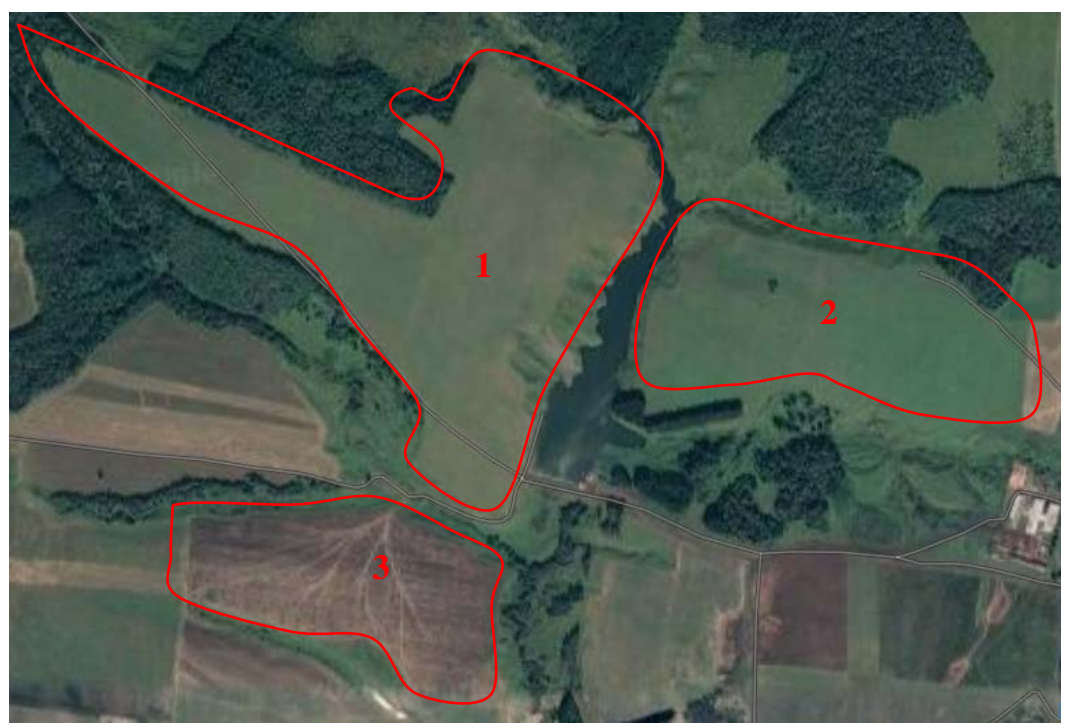

Fig. 1. Fragment of the location of the experimental catchment area with distributed control fields (three agricultural plots)in the Morgaushsky district of the Chuvash Republic

The main advantages of this device in comparison with other roughness measurement methods are $[8,9]$ :

1) high accuracy of the obtained data $(0.5 \mathrm{~mm})$;

2) the soil surface of the elementary plot remains unchanged during and after measurements;

3) profile data are loaded directly into the computer program, so no pre-processing is required (in polar coordinates [9] and in the Excel table);

4) the device is reliable, simple, mobile (1.5 m x $0.3 \mathrm{~m} \times 1.4 \mathrm{~m}$ - its overall dimensions in operation, and $0.3 \mathrm{~m} \times 0.3 \mathrm{~m} \times 1.5 \mathrm{~m}$ - in transportation), so it can easily be used in the field;

5) collection and storage of a large number of profiles (one profile contains from 5000 to 40000 points depending on the speed of the sensor rotation). 


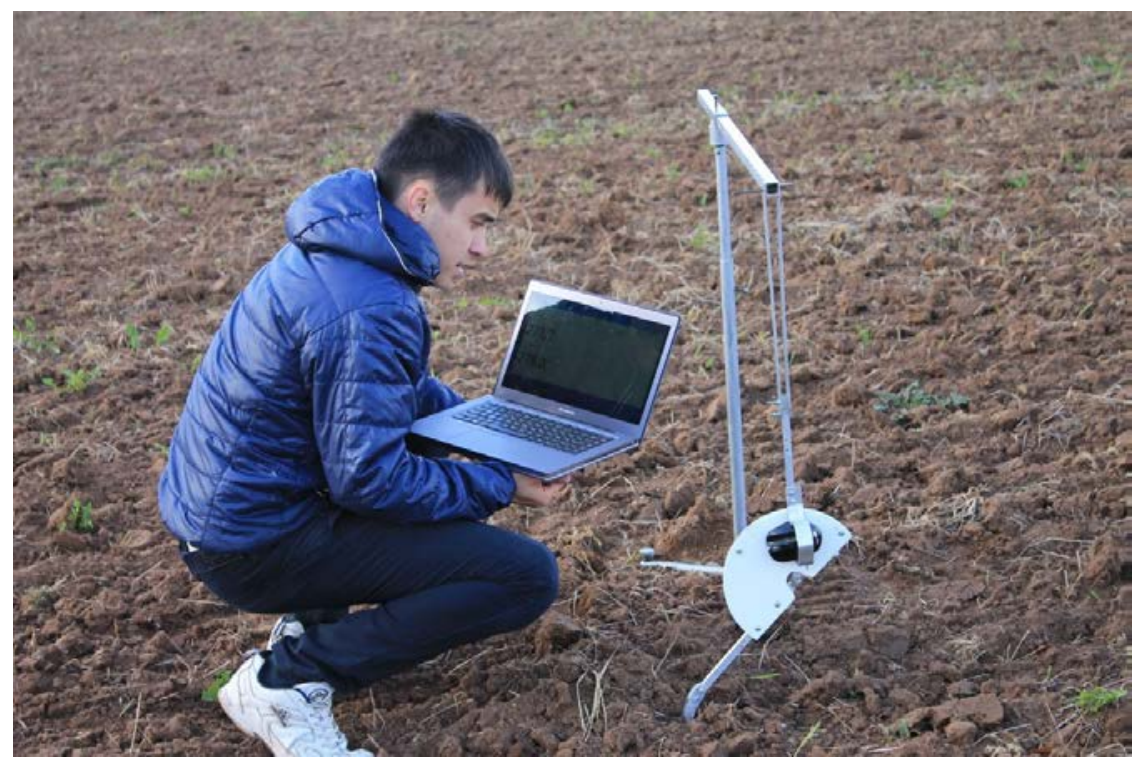

Fig. 2. Profilograph: $a$ - general view; $b$ - in operation.

The moving average method was used to determine the main parameters of slope, ridgeness and roughness of the day soil surface for each tillage method [17]. The moving average method allows you to determine the moving average, which is numerically equal to the arithmetic value of the original function for a given period and is determined by the expression:

$$
S M A_{k}=\frac{1}{n_{c}} \sum_{i=0}^{n-1} h_{k-i}=\frac{h_{k}+h_{k-1}+\ldots+h_{k-n+1}}{n_{c}}
$$

where $S M A_{k}$ - the value of the moving average at point $\mathrm{k} ; n_{c}$ - the number of point values obtained by scanning the surface as a of function for calculating the moving average (averaging interval); $h_{k-1}$ - the value of the resulting function at point k-1.

\section{Results and discussion}

The measured data were averaged according to a different number of point values obtained by scanning the surface, as a function for calculating the moving average from 2 to 1500 and $-10,500$ and 1000 were selected to determine the main morphological parameters of the surface. To determine the roughness, ridgeness and slope of the surface according to the measured data, we calculate the moving average based on the number of periods equal to 10,500 and 1000 , respectively, using the following expressions:

$$
\begin{gathered}
S M A_{10}=\frac{h_{k}+h_{k-1}+\ldots+h_{k-9}}{10}, \\
S M A_{500}=\frac{h_{k}+h_{k-1}+\ldots+h_{k-499}}{500}
\end{gathered}
$$




$$
S M A_{1000}=\frac{h_{k}+h_{k-1}+\ldots+h_{k-999}}{1000} .
$$

Using the obtained expressions (2), (3) and (4), we construct a moving average function of these parameters on the graph of the day surface profile of the tilled soil. The surface roughness for the elementary plot according to the expression (2) was $4 \mathrm{~mm}$ (figure 3). The surface ridgeness is formed by technological furrows, the height of which is $16 \mathrm{~mm}$ (figure 4), and the slope of the elementary plot was 0.198 or 5,6 degrees (figure 5).

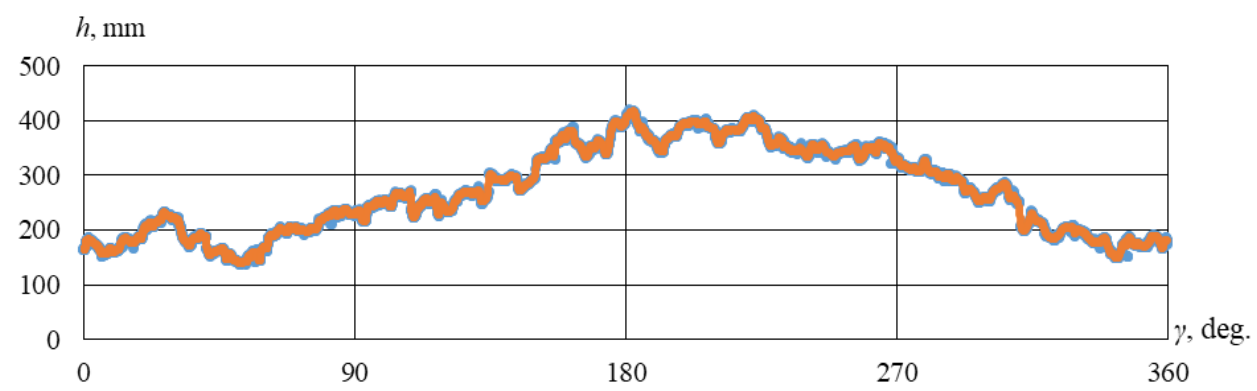

Fig. 3. Graph of the function of the actual surface profile of the tilled soil with averaging to determine its roughness

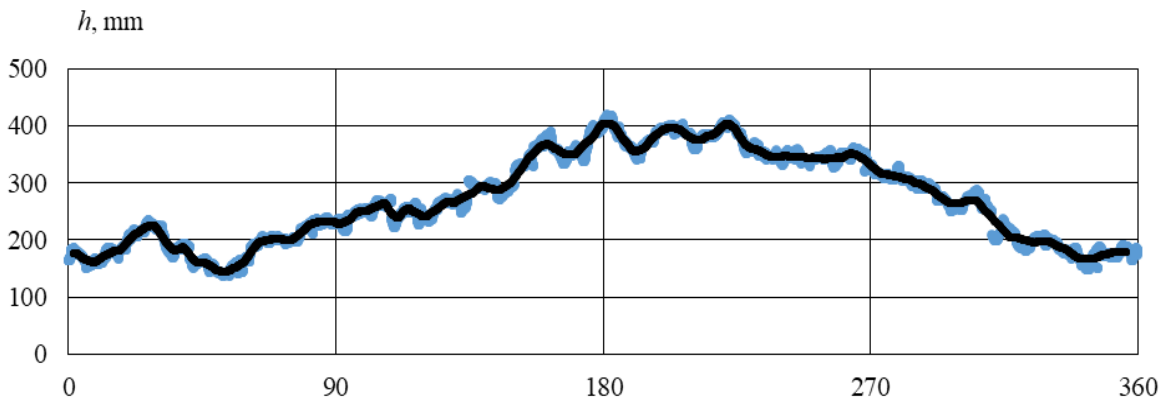

Fig. 4. Graph of the function of the actual profile of the surface of the tilled soil with averaging to determine its ridgeness.

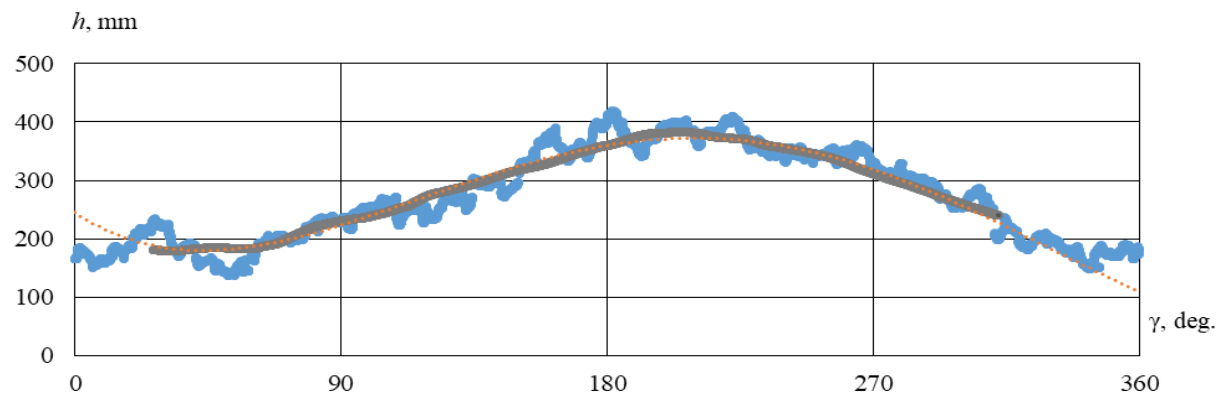

Fig. 5. Graph of the function of the actual surface profile of the tilled soil with averaging to determine its slope 
The dependence of the values of the measured parameters on the profile length resulted from the variety of the surface roughness nature [2]. Surface microtopography consists of a superposition of soil components with varying frequencies. Thus, short sections of the surface profile cannot reflect those low-frequency roughness components that are noticeable only when the profiles are long enough. In order to compare these values due to scaling performed between different profiles and different tillage methods, a base length was calculated based on the number of measured points for each morphological parameter.

To determine the optimal base number of measurement points when determining the roughness and ridgeness of the surface in the circle, the segmental method was used, i.e. the number of actual points (5273) obtained in the circle was gradually reduced in the calculations, applying to the expression (1). Thus, we obtained the dependences of changes of the calculated value of roughness $\Delta$ (Figures 6 ) and ridgesness $w$ on the number of measurement points in the circle.

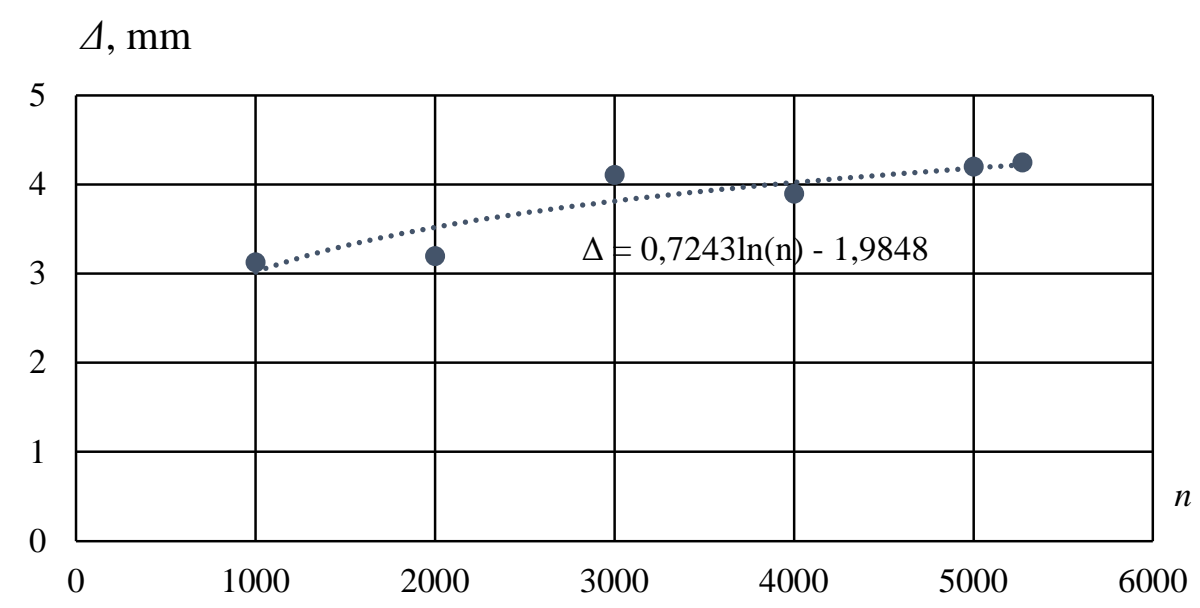

Fig. 6. Change in the calculated roughness value from the number of measurement points in the circle

According to the presented graphs, it can be observed that the obtained values of roughness and ridgeness of the surface of the tilled soil significantly depend on the length of the studied profile, determined by the number of measurements $n$. We obtained 5273 data points per one turn of the device on a $6.3 \mathrm{~m}$ long profile ( 1 measurements are made per $1 \mathrm{~mm})$. It can be seen that the estimated surface roughness varied from $3.1 \mathrm{~mm}$ to $4.3 \mathrm{~mm}$, and the ridgeness $-12 \ldots 21 \mathrm{~mm}$. As the length of the measured profile increases (from 2000 to 5000 points), the parameters of the calculated roughness and ridgeness first increase sharply, and then vary around the asymptotic value taken as the true value -4.2 $\mathrm{mm}$ and $14.8 \mathrm{~mm}$, respectively.

When the measured profile length is about $1.3 \mathrm{~m}$ or less (not more 2000 points), the parameters of the tilled soil cover are not considered important. However, they are more critical for ploughed soil than for harrowed soil. On flat surfaces, the base profile length of $2.5 \mathrm{~m}$ may be sufficient to adequately calculate the parameters of the day soil surface when the device turns at $150 \ldots 180$ degrees. This can be explained by the absence of lowfrequency roughness components on flattened surfaces. Similar results were obtained by Taconet and Ciarletti [6], who assessed the effect of clod size on the accuracy of several roughness parameters using photogrammetric observations for plowed soil and crops. 


\section{Conclusions}

Thus, based on the results obtained in this study, several conclusions can be drawn:

1. Tillage operations significantly affect the value and variability of parameters of the day soil surface. The plowed surface showed not only high values of roughness and ridgeness, but also their high variability, which should be taken into account when monitoring tillage operations and simulating hydrological processes on slope lands, using the moving average method.

2. The accuracy of the obtained values of roughness and ridgeness of the tilled soil surface depends significantly on the length of the studied profile, determined by the number of measurements.

3. On flatter surfaces after harrowing, the base profile length of 2.5 meters may be sufficient to adequately calculate the main parameters of the day soil surface.

The above allows us to recommend the moving average method for evaluating the morphological parameters of the day surface of the tilled soil; to set the base profile length of more than 2.5 meters to improve the accuracy of the obtained values during the control process.

The research was carried out within the framework of the grant of the Russian Federation President to support young Russian scientists MD-1198.2020.8, agreement no.075-15-2020-228.

\section{References}

1. K. Helming, M.J.M. Romkens, S.N. Prasad, Surface roughness related processes of runoff and soil loss: a flume study, Soil Science Society of America Journal, 62 (1), pp. 243-250 (1998)

2. S.A. Vasilev, I.I. Maksimov, Agricultural landscape reclamation of slope lands, Novoye Vremya, p. 306 (2019)

3. J. Alvarez-Mozos et al., Implications of scale, slope, tillage operation and direction in the estimation of surface depression storage, Soil \& Tillage Research, 111, pp.142-153 (2011)

4. M.J.M. Romkens, K. Helming, S.N. Prasad, Soil erosion at different precipitation rates, surface roughness, and soil water regimes, CATENA, 46 (2-3), pp. 103-123 (2002)

5. R. R. Allmaras, General porosity and random roughness of the inter-row zone under the influence of soil treatment, Agricultural Research Service, p. 22 (1966)

6. O.Taconet, V. Ciarletti, Estimating soil roughness indices on a ridge-andfurrow surface using stereo photogrammetry, Soil \& Tillage Research, 93 (1), pp.64-76 (2007)

7. M.A. Elbasit, H. Anyoji, H. Yasuda, S. Yamamoto, Potential of low cost close-range photogrammetry system in soil microtopography quantification, Hydrological Processes, 23 (10), pp.1408-1417 (2009)

8. S.A. Vasilev, Development of a method and a Profile Meter for assessing reclamation technologies on slope agricultural landscapes Bulletin of Nizhnevolzhsky Agricultural University complex, № 3 (43), pp. 220-226 (2016)

9. S.A. Vasilev, Substantiation of constructive-technological parameters of the profile meter to control reclamation technologies on slope agricultural landscapes, Scientific journal of the Russian research Institute of land reclamation problems, № 4(24) pp.4054. (2016)

10. I. Takken, G. Govers, A.Steegen, J. Nachtergaele, J. Guerif, The prediction of runoff flow directions on tilled fields, Journal of Hydrology, 248 (1-4), pp.1-13 (2001) 
11. S. A. Semenov, S. A. Vasiliev, I. I. Maximov, Features of implementation and prospects of application of digital farming technologies in the agro-industrial complex, Bulletin of the Chuvash state agricultural Academy, № 1 (4), pp.69-76. (2018)

12. A. A. Vasiliev et al., Anti-erosion contour tillage with machine-tractor units on agricultural landscapes of slope lands, Bulletin of the NGIEI, № 5 (84), pp.43-54 (2018)

13. I. I. Maximov et al., Method for determining the direction of water flow on the agricultural landscape of slope lands, Bulletin of the Kazan State Agrarian University, № 4 (46), pp.72-77 (2017)

14. L. P. Sergeev, Morgaushskiy district: Brief encyclopedia, Chuvash publishing house, p.174 (2002)

15. V. A. Sysuev, I. I. Maksimov, V. I. Maksimov, V. V. Alekseev, Catchment area of small rivers as an object of anthropogenic agricultural landscape (on the example of the Tsivil river), Agrarian Science of the Euro-North-East, № 5(36), pp. 59-65 (2013)

16. V. I. Maksimov, I. I. Maksimov, A. N. Mikhailov, V. V. Alekseev, Energy (thermodynamic) approach to the evaluation of tillage machines with active working units, Bulletin of the International Academy of agricultural education, № 17, pp. 68-71 (2013)

17. F. D. Samuilov et al., Implementation of a method for determining and processing data on the parameters of the underlying surface of agricultural landscapes slope lands, Bulletin of the Kazan State Agrarian University, v. 13, № 2 (49), pp. 81-85 (2018) 